\title{
Selection of Numerical Methods and their Application to the Thermo-Ecological Life Cycle Cost of Heat Exchanger Components
}

\author{
Lucyna Czarnowska ${ }^{1 *}$, Wojciech Litwin ${ }^{2}$, Wojciech Stanek ${ }^{1}$ \\ ${ }^{1}$ Silesian University of Technology, \\ Institute of Thermal Technology, Gliwice, Poland \\ e-mail: lczarnowska@polsl.pl \\ ${ }^{2}$ Monolith Solution, Siemianowice, Poland
}

\begin{abstract}
Cite as: Czarnowska, L., Litwin, W., Stanek, W., Selection of Numerical Methods and their Application to the Thermo-
Ecological Life Cycle Cost of Heat Exchanger Components, J. sustain. dev. energy water environ. syst., 3(2), pp 131-139, 2015, DOI: http://dx.doi.org/10.13044/j.sdewes.2015.03.0010
\end{abstract}

\begin{abstract}
Thermo-Ecological Cost with the inclusion of Life Cycle (TEC-LC) is defined as the cumulative exergy consumption of non-renewable natural resources associated with any product and its life cycle, taking into account the necessity to prevent and compensate losses caused by depletion of natural resources and the release of harmful substances into the environment. The problem of collecting data for solving TEC-LC equations is not the only one which can be faced in determining this indicator. The selection of the calculation method could also affect obtained results due to the accuracy of the selected algorithm. Numerical stability is particularly important in the case of large sets of data and in this case operations on large matrixes. The issue with a set of TEC-LC balanced equations is examined and compared on the basis of heat exchanger components.
\end{abstract}

\section{KEYWORDS}

Numerical methods, Thermo-ecological cost, Heat exchanger, Math.NET Numerics, Iterative matrix solvers.

\section{INTRODUCTION}

Initially in TEC-LC the Gaussian Elimination was used; however, in this method there is a risk of numerical instability which magnifies the round off and truncation errors. In many cases there could be different ways that are algebraically equivalent, for performing the same calculation; moreover, through performing these calculations on computers it is possible to obtain different results due to numerical instability which occurs when the selected algorithm increases the error of approximation. In case of Gaussian Elimination mentioned problem could appear for matrices that are not diagonally dominant or positive-definite. This condition is difficult to fulfil because there are a lot of industry brunches not significantly connected to each other which results in many zeroes and they cannot be eliminated from the matrix. The thermo-ecological cost life cycle should contain as many connections between branches as possible in order to reflect the idea from the cradle to the grave. Only through constant replenishment of databases it is possible to obtain more effective results regarding new products, hence the matrix and vector inputs is bigger and bigger. Therefore, it is important to use the most accurate numerical method; however, this matrix does not meet all requirements for any method. For this reason, LU factorization, singular value decomposition, eigenvalues and eigenvectors of a real matrix, Cholesky factorization, transpose free quasi-minimal

\footnotetext{
* Corresponding author
} 
residual, multiple-lanczos bi-conjugate gradient stabilized, the composite matrix solver has been analysed. The results obtained by various methods are convergent. In the article the impact of the chosen numerical method of calculations on the TEC values of the heat exchanger components in the full life cycle is shown. The calculated values of TEC could be used to optimize the design parameters of thermal process devices.

\section{FUNDAMENTALS OF LIFE CYCLE THERMO-ECOLOGICAL COST}

Thermo-Ecological Cost (TEC) is one of the environmental analysis methods for estimating the impact of human activity on the surroundings. According to ref. $[1,2]$, thermo-ecological cost is the cumulative exergy consumption of non-renewable natural resources associated with any product, taking into account the necessity to prevent and compensate losses caused by the release of harmful substances into the environment. The TEC is calculated based on a set of equations:

$$
\rho_{j}+\sum_{i}\left(f_{i j}-a_{i j}\right) \rho_{i}-\sum_{l} a_{l j} \rho_{l}=\sum_{k} p_{k j} \zeta_{k}+\sum_{f} b_{f j}+\sum_{m} b_{m j}
$$

From the eq. (1) the TEC of $j^{\text {th }}$ considered product from $c^{\text {th }}$ region or country is calculated $\left(\rho_{j, c}\right)$. The input data, which should be prepared before starting the calculation, is the coefficients of the consumption of $i^{\text {th }}$ domestic or imported products $\left(a_{i j}\right)$, the coefficients of $l^{\text {th }}$ construction and disposal phases $\left(a_{l j}\right)$, the coefficient of by-production $\left(f_{i j}\right)$, the amount of $k^{\text {th }}$ waste substance $\left(p_{k j}\right)$, the thermo-ecological cost of $k^{\text {th }}$ harmful substance from $c^{\text {th }}$ region rejected to the environment $\left(\zeta_{k, c}\right)$, the exergy of the $f^{\text {th }}$ fuel and $m^{\text {th }}$ mineral $\left(b_{f j}, b_{m j}\right)$. However, from the set of eq. (1), the thermo-ecological cost of $i^{\text {th }}$ products consumed in $j^{\text {th }}$ considered branch and thermo-ecological cost of $l^{\text {th }}$ connected with investment and dismantling phase of the product are also obtained. The matrix form of the eq. (1) is as follows:

$$
\mathrm{AP}=\mathrm{B}
$$

where are input matrix:

$$
\mathrm{A}=\left[f_{i j}\right]-\left[a_{i j}\right]-\left[a_{l j}\right]+\left[i_{j j}\right] \text { and }\left[i_{j j}\right]=\left[a_{j j}\right]
$$

input vector:

$$
\mathrm{B}=\left[p_{k j}\right]^{T}\left[\zeta_{k}\right]+\left[b_{f j}\right]^{T}+\left[b_{m j}\right]^{T}
$$

and output vector:

$$
\mathrm{P}=\left[\rho_{i}\right]+\left[\rho_{j}\right]+\left[\rho_{l}\right]
$$

The data for input matrix could be prepared based on the country statistical data such as Polish Central Statistical Office [3, 4], EcoInvent data base [5, 6] or directly from the manufacturing companies' data. The process of gathering data for input vector in case of the harmful substance is the same as in the case of the input matrix's data. The exergy vector could be prepared based on [7-9]; whereas, the thermo-ecological cost of harmful substance is obtained from the following formula: 


$$
\zeta_{k, c}=\frac{B_{c}^{C} w_{k, c}}{G D P_{c}-\sum_{k} P_{k, c} w_{k, c}}
$$

The subscript $)_{C}$ is added to distinguish harmful substance from different countries; however, in the eq. (1) the subscript $)_{j}$ as well as $\left.\left.)_{k},\right)_{f},\right)_{m}$ indicates not only different products, but also production of these goods in different localizations. The superscript $)^{C}$ means that it is the exergy consumption of non-renewable natural resources $\left(B_{C}{ }^{C}\right)$ in opposite to ref. [1] where in thermo-ecological cost of harmful substance the exergy extraction $(B)$ was taken into account.

The $B_{C}{ }^{C}$ is the annual exergy consumption of all non-renewable natural resources such as coal, oil, gas, iron ore, copper ore, nickel ore, and other, which could be obtained from ref. [10]. In general, exergy measures the quality of energy; however, it also gives the real value of all fuels and minerals. Additionally, to calculate the eq. (6), the gross domestic product $\left(G D P_{c}\right)$ and a monetary index of harmful substances $\left(w_{k, c}\right)$ for all specific countries should be given [11, 12].

The idea of Thermo-Ecological Cost balance with inclusion of Life Cycle (TEC-LC) is presented in Figure 1, where the $j^{\text {th }}$ considered product is a heat exchanger.

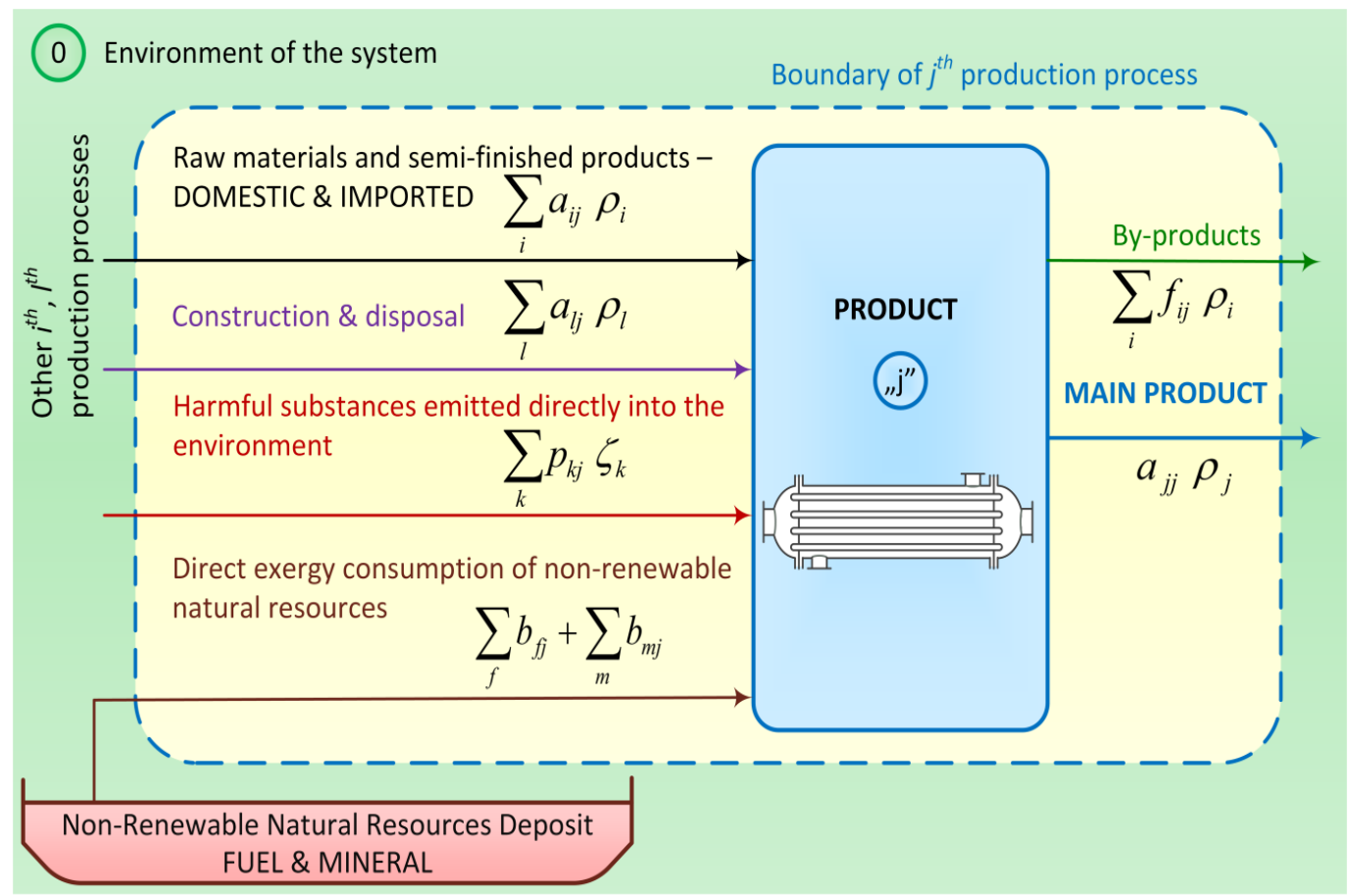

Figure 1. Thermo-ecological cost balance with inclusion of life cycle

The Shell and Tube Heat Exchanger (STHEX) is used when larger amounts of fluid are processed like for example in the case of condenser. Three essential phases of the STHEX life cycle such as construction, operation and disposal could be distinguished. In general, construction parts and materials of shell and tube heat exchanger [13] are:

- Tubes - made from low carbon steel, copper, copper-nickel, stainless steel, or titanium;

- Tube sheets (rounded and flattened sheets of metal with holes) - made from the same materials as tubes;

- Shell assembly - made from rolled plate steel, in some cases more advanced material are used; 
- Bonnets and end channels - poured from iron, steel, bronze, nickel plated, or stainless steel;

- Baffles - made from material which is coherent with material of shell assembly.

The operational phase of STHEX required the electricity for pumping and some replacement parts during maintenance. However, during the disposal phase, the HEX components are easily recycled.

All production processes of the mentioned components, generation of electricity and recycling process are a part of the global economy and influence on the environment as they consume the natural resources and pollute the air, water and ground. In order to calculate the cumulative influence of one product on the environment, which in this case is TSHEX, the global economy should be taken into account. This product is used in different regions of the world, although the availability of ores is limited. Extraction of various ores, its transportation to the place of processing, and then the obtained finished product is delivered to a place where it is used. The operation of TSHEX involves the use of electricity, which nowadays is generated by using mainly non-renewable fossil fuels, the availability of which is also limited. Hence, the better the matrix of linked processes, the more reliable the obtained results. This implies, that TEC-LC based on many linked processes so the appropriate numerical method should be indicated.

\section{SELECTED NUMERICAL METHODS AND THEIR APPLICATION TO THE TEC-LC ALGORITHM}

The size of the input matrix is about 4,000 $\times 4,000$ elements, more of them are equal to zero. Some of them are represented by a very small number, since depending on the process, different quantity of the various materials are required. The diagonal values are equal one $\left(a_{j j}=1\right)$, because from each equation the TEC-LC value for the $j^{\text {th }}$ product is obtained.

When performing such complex calculations using the specified floating-point data [14] round-off, truncation and discretization error could occur. These errors would occur because floating point in computer science is a way of approximation of a real number in such a way that would allow to present a wide range of values. These real numbers are approximated to a fixed number of digits and scaled using exponent. Because of that values close to zero are presented with higher precision than larger ones; therefore, not all values in the data type range can be represented exactly. The completely other problem is numerical instability which could lead to exponential growth of computation errors, but this could be eliminated by checking a few numerical methods available.

The C Sharp (C\#) programming language and relational Microsoft SQL Server 2012 Database (MSSQL) are used to calculate the TEC-LC algorithm. The data types chosen for calculations where float in MSSQL with approximate range defined as $-1.79 \times 10^{308}$ to $-2.2 \times 10^{-308}, 0$ and $2.23 \times 10^{-308}$ to $1.79 \times 10^{308}$ and double in $\mathrm{C} \#$ with approximate range $\pm 5.0 \times 10^{-324}$ to $\pm 1.7 \times 10^{308}$.

The main superiorities of $\mathrm{C} \#$ programming language over others such as FORTRAN or Engineer Equation Solver program:

- Is free of charge;

- Has easy way to connect to MSSQL Server Database [15], which is also free of charge;

- Has wide access to libraries and support, as it is used by many programmers around the world [15];

- Has build in parallelism;

- Is defined by ISO [16] and Ecma standard [17]. 
The flow of data, between MSSQL and C\# to obtain the TEC-LC results, is presented in Figure 2.

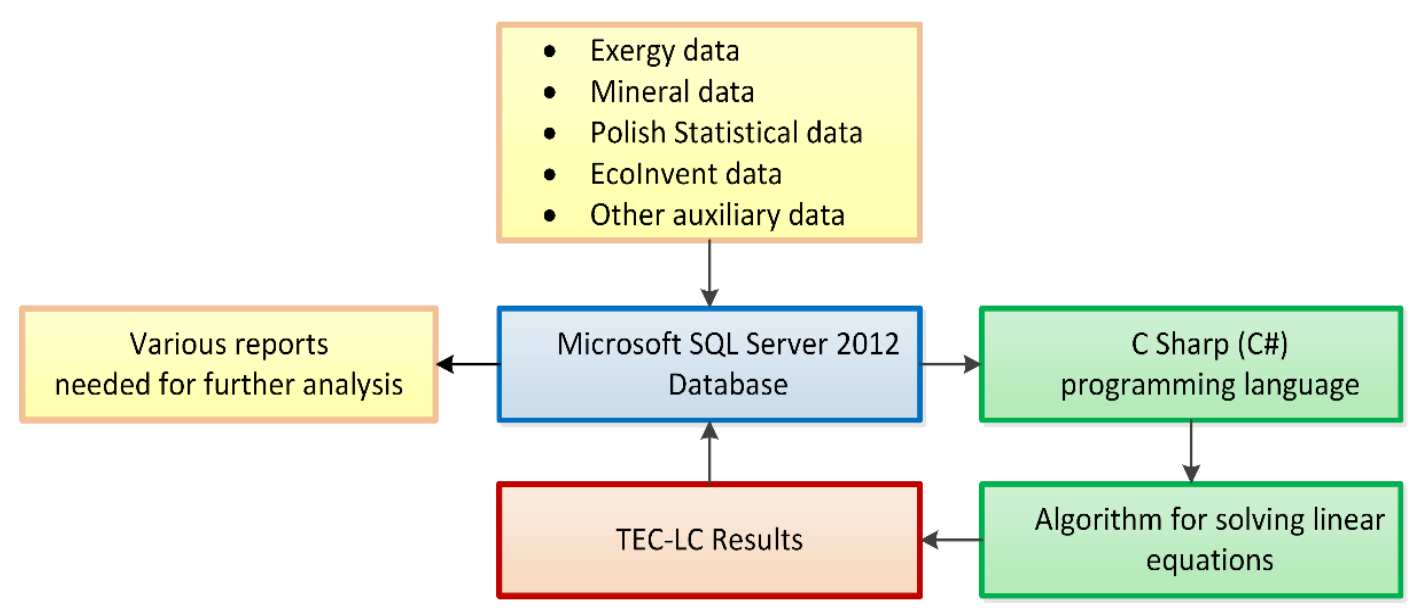

Figure 2. Flow data in TEC-LC algorithm

The following algorithms from Math.NET Numerics open source library [18] have been checked for TEC-LC balances:

- Algorithm for solving linear sets of equations:

○ LU factorization (LU);

- Singular Value Decomposition (SVD);

- Eigenvalues and Eigenvectors of a real matrix (EVE);

○ Cholesky factorization.

- Iterative matrix solvers:

○ Transpose Free Quasi-Minimal Residual (TFQMR);

- Multiple-lanczos Bi-Conjugate gradient Stabilized (MBCS);

- Composite Matrix Solver (CMS).

The Cholesky factorization algorithm is not adequate to TEC-LC input data as the matrix A should be symmetric and positive defined. Also, CMS algorithm is not appropriate for TEC-LC balances. Moreover, the EVE gives the completely impossible results which differ from the results of the other four methods. The time of solving TEC-LC balances by LU, SVD, TFQMR, MBCS is presented in Table 1.

Table 1. The time of solving TEC-LC balances

\begin{tabular}{cccc}
\hline \multirow{2}{*}{ Name of algorithm } & \multicolumn{3}{c}{ Processing time, seconds } \\
& Min & Max & Average \\
\hline Transpose free quasi-minimal residual & 9 & 244 & 47 \\
LU factorization & 249 & 478 & 407 \\
Multiple-lanczos bi-conjugate gradient stabilized & 149 & 9,754 & 1,705 \\
Singular value decomposition & 1,620 & 2,818 & 1,889 \\
\hline
\end{tabular}

The processing time varies as the fuel, mineral and emission part were calculated separately and the total TEC-LC was obtained by summing the partial TEC-LC. The iterative transpose free quasi-minimal residual method is the fastest way to calculate the TEC-LC from the presented algorithms; however, it has two preconditions defined such as: 
- Stop the calculation if residuals are below $1 \times 10^{-10}$;

- 1,000 iterations which in rare cases is not enough to obtain the reasonable results.

\section{TEC-LC OF HEAT EXCHANGER COMPONENTS}

The results obtained by the LU factorization, TFQMR and MBCS algorithm are the same for every value, and selected material components of STHEX are presented in Table 2.

Table 2. The TEC-LC results of STHEX components

\begin{tabular}{cccc}
\hline Material component & Remarks & Units & TEC-LC \\
\hline Bronze, at the plant & $E$ & {$[\mathrm{MJ} / \mathrm{kg}]$} & 60.00 \\
Bronze, cast & $\mathrm{E}+\mathrm{P}$ & {$[\mathrm{MJ} / \mathrm{kg}]$} & 61.04 \\
Copper, at the regional storage & $\mathrm{E}$ & {$[\mathrm{MJ} / \mathrm{kg}]$} & 42.03 \\
Copper, sheet rolled & $\mathrm{E}+\mathrm{P}$ & {$[\mathrm{MJ} / \mathrm{kg}]$} & 58.65 \\
Iron, cast & $\mathrm{E}+\mathrm{P}$ & {$[\mathrm{MJ} / \mathrm{kg}]$} & 30.05 \\
Stainless steel sheet, selective coating, black chrome & - & {$\left[\mathrm{MJ} / \mathrm{m}^{2}\right]$} & 8.24 \\
Steel, converter, low-alloyed, at the plant & $\mathrm{E}$ & {$[\mathrm{MJ} / \mathrm{kg}]$} & 39.59 \\
Steel, converter, unalloyed, at the plant & $\mathrm{E}$ & {$[\mathrm{MJ} / \mathrm{kg}]$} & 31.87 \\
Steel, low-alloyed, at the plant & $\mathrm{E}$ & {$[\mathrm{MJ} / \mathrm{kg}]$} & 32.55 \\
Steel, hot rolled & $\mathrm{E}+\mathrm{P}$ & {$[\mathrm{MJ} / \mathrm{kg}]$} & 37.57 \\
Steel sheet, rolled & $\mathrm{E}+\mathrm{P}$ & {$[\mathrm{MJ} / \mathrm{kg}]$} & 38.76 \\
Titanium zinc plate, without pre-weathering, at the plant & $\mathrm{E}+\mathrm{P}$ & {$[\mathrm{MJ} / \mathrm{kg}]$} & 69.47 \\
\hline
\end{tabular}

$\mathrm{E}-$ extracting, $\mathrm{E}+\mathrm{P}-$ extracted material undergoing a process

The higher the TEC-LC value the more influence on the environment is done by the component. The stainless steel has the lower value; however, it is expressed in $\mathrm{MJ} / \mathrm{m}^{2}$ and it could not be compared with other components until the unit is comparable. Moreover, components which are identified by E (extracting), are less processed than components identified by $\mathrm{E}+\mathrm{P}$ (extracted material undergoing a process). To analyse the heat exchanger the exact amount of mass of the individual components should be known. Additionally, during operational phase the electricity is used, which is strongly dependent on the location. The Figure 3 shows the TEC-LC of the electricity production mix in selected regions.

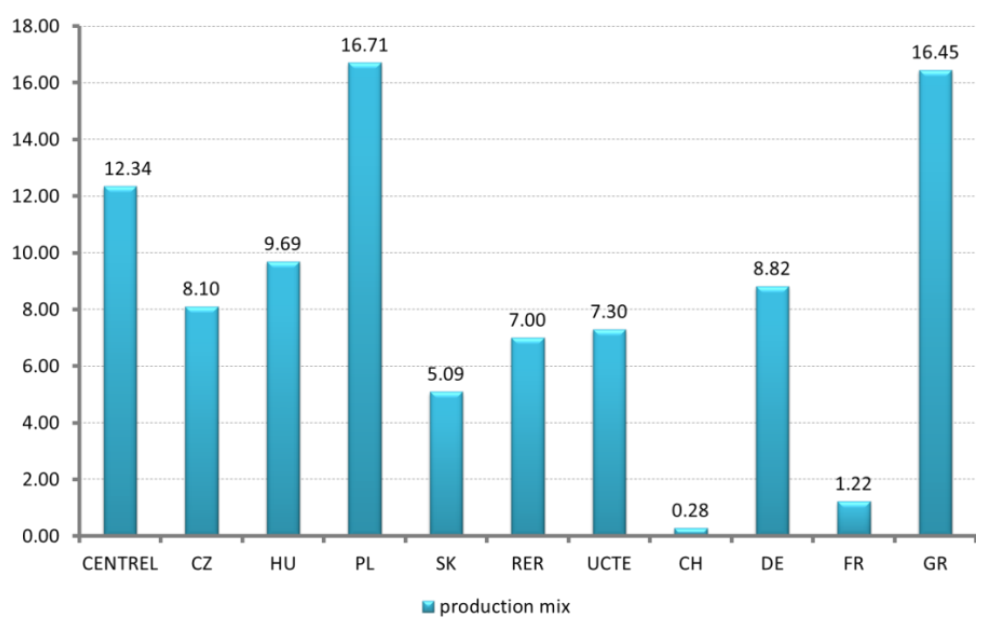

Figure 3. TEC-LC of electricity in selected regions $\mathrm{MJ} / \mathrm{kWh}$ 
Apart from eight countries, three additional regions are presented and the abbreviations of them mean:

- RER - Europe (28 countries);

- CENTRAL - Central European power association (CZ, HU, PL, SK);

- UCTE - Union for the Coordination of the Transmission of Electricity (23 countries).

As is shown in Figure 3 the lower value of TEC-LC is in Switzerland; however, the highest value is in Poland. In Poland most of the electricity is generated from coal and gas; whereas in Switzerland the non-fossil energy is used.

\section{CONCLUSIONS}

Numerical results obtained with the different algorithms were compared with each other to verify the values and check if any numerical instability occurs. The values generated by TFQMR, LU and MLBCG algorithms were exactly the same for every vector, the only difference was noted in the case of SVD algorithm. For extreme low values because of truncation errors this difference was as high as $5.948 \times 10^{9} \%$ for whey at the dairy, $1.7917 \times 10^{9} \%$ for disposal, non-sulfidic tailings or $6.1815 \times 10^{7} \%$ of electricity from waste, at municipal waste incineration plant. However, such great precision is not required for TEC-LC process and therefore obtained results were rounded up to six decimal places and again compared between algorithms, which resulted in the average difference of $0.113 \%$.

The TEC-LC of the material components of the shell and tube heat exchanger and the extracted minerals needed to prepare these materials have been analysed. The highest TEC-LC of presenting minerals has bronze; whereas, the highest TEC-LC of final component has a titanium zinc plate. The higher the TEC-LC the higher interference of the component with the surrounding environment. The components represent the design phase; however, the consumption of electricity represents the operational phase, where the finished STHEX is used. Depending on the localization of the STHEX the operational phase will affects the environment differently, which means in regions where is higher usage of the non-renewable energy such as coal, gas or oil the influence is higher than in regions where more renewable energy is used.

\section{NOMENCLATURE}

$\begin{array}{lll}a & \text { consumption of products per considered product } & {[\mathrm{kg} / \mathrm{kg}]} \\ b & \text { specific chemical exergy } & {[\mathrm{MJ} / \mathrm{kg}]} \\ B & \text { total chemical exergy } & {[\mathrm{MJ}]} \\ f & \text { production of by-products per considered product } & {[\mathrm{kg} / \mathrm{kg}]} \\ p & \text { released harmful substations per considered product } & {[\mathrm{kg} / \mathrm{kg}]} \\ w & \text { monetary index of harmful substances } & {[\mathrm{EUR} / \mathrm{kg}]} \\ G D P & \text { Gross Domestic Product } & {[\mathrm{EUR}]} \\ T E C-L C & \text { Thermo-Ecological Cost in full Life Cycle } & {[\mathrm{MJ} / \mathrm{kg}]}\end{array}$

\section{Greek letters}

$\begin{array}{lll}\zeta & \text { thermo-ecological cost of harmful substance } & {[\mathrm{MJ} / \mathrm{kg}]} \\ \rho & \text { thermo-ecological cost } & {[\mathrm{MJ} / \mathrm{kg}]}\end{array}$

\footnotetext{
Abreviations

C\# C Sharp Programming Language

CMS Composite Matrix Solver (iterative matrix solvers)

E Extraction of Material
}

$[\mathrm{MJ} / \mathrm{kg}]$ 


$\begin{array}{ll}\text { E+P } & \begin{array}{l}\text { Extracted Material Undergoing a Process } \\ \text { Eigenvalues and Eigenvectors of a real matrix (algorithm for solving linear } \\ \text { equations) }\end{array} \\ \text { ISO } & \begin{array}{l}\text { International Organization for Standardization } \\ \text { MBCS }\end{array} \\ \text { Multiple-lanczos Bi-Conjugate Gradient Stabilized (iterative matrix solvers) } \\ \text { MSSQL } & \text { Microsoft SQL Server 2012 Database } \\ \text { SQL } & \text { Structured Query Language } \\ \text { STHEX } & \text { Shell and Tube Heat Exchanger } \\ \text { SVD } & \text { Singular Value Decomposition (algorithm for solving linear equations) } \\ \text { TFQMR } & \text { Transpose Free Quasi-Minimal Residual (iterative matrix solvers) }\end{array}$

\section{ACKNOWLEDGMENTS}

This paper was prepared with the support of the Research Project N N512 455540, financed by the Polish science budget resources.

\section{REFERENCES}

1. Szargut, J., Minimization of the consumption of Natural Resources; Bulletin of the Polish Academy of Sciences, Technical Science, Vol. 26, No. 6, pp 41-45, 1978.

2. Szargut, J., Ziębik, A., Stanek, W., Depletion of the Non-renewable Natural Exergy Resources as a Measure of the Ecological Cost, Energy Conversion and Management, Vol. 42, Issues 9-12, pp 1149-1163, 2002., http://dx.doi.org/10.1016/S0196-8904(02)00005-5

3. Central Statistical Office, Berent-Kowalsa, G., et al., Materials Management 2006, 2007, 2008, 2009, 2010, http://www.stat.gov.pl/gus/5840_4952_ENG_HTML.htm, [Accessed: 20-September-2013]

4. Central Statistical Office, Tkaczyk, W., Berent-Kowalsa, G., Kacprowska, J., Gilecki, R., Energy Statistics 2004, 2005, 2006, 2007, 2008, 2009, 2010, 2011, Warszawa, http://www.stat.gov.pl/gus/5840_5314_PLK_HTML.htm,

[Accessed: 20-September-2013]

5. Classen, M., Althaus, H. J., Blaser, S., Tuchschmid, M., Jungbluth, N., Doka, G., Faist Emmenegger, M., Scharnhorst, W., Life Cycle Inventories of Metals, Final report, Ecoinvent data v2.1, No. 10, EMPA, Dübendorf, Switzerland, 2009., www.ecoinvent.org, [Accessed: 20-September-2013]

6. Dones, R., Bauer, C., Bolliger, R., Burger, B., Faist Emmenegger, M., Frischknecht, R., Heck, T., Jungbluth, N., Röder, A., (2007) Life Cycle Inventories of Energy Systems: Results for Current Systems in Switzerland and other UCTE Countries, Ecoinvent report No. 5. Paul Scherrer Institut Villigen, Swiss Centre for Life Cycle Inventories, Dübendorf, 2007.

7. Moris, D. R., Szargut, J., Standard Chemical Exergy of Some Elements and Compounds on the Planet Earth, Energy, Vol. 11, No. 8, pp 733-755, 1986., http://dx.doi.org/10.1016/0360-5442(86)90013-7

8. Szargut, J., Exergy Method, Technical and ecological applications, WIT Press, Boston, 2005.

9. Valero, A., Valero, Al., Exergoecology: A Thermodynamic approach for Accounting the Earth's Mineral Capital, The Case of Bauxite-aluminium and Limestone-lime Chains, Energy, Vol. 35, Issue 1, pp 229-238, 2010., http://dx.doi.org/10.1016/j.energy.2009.09.013

10.Brown, T. J., Idoine, N. E., Mills, A. J., Shaw, R. A., Hobbs, S. F., Bide, T., European Mineral Statistics 2006-10, A Product of the World Mineral Statistics Database, Keyworth, Nottingham, British Geological Survey 2012, http://nora.nerc.ac.uk/17613/1/EMS2006-2010.pdf, [Accessed: 20-September-2013] 
11.Czarnowska, L., Frangopoulos, C. A., Dispersion of Pollutants, Environmental Externalities due to a Pulverized Coal Power Plant and their Effect on the Cost of Electricity, Energy, Vol. 41, pp 212-219, 2012., http://dx.doi.org/10.1016/j.energy.2011.08.004

12.Stanek, W., Czarnowska, L., Environmental Externalities and its Influence on the Thermo-ecological Cost, International Journal of Sustainable Water and Environmental Systems, Vol. 4, No. 1, pp 51-58, 2012., http://dx.doi.org/10.5383/swes.04.01.006

13. Heat exchanger Materials and Construction, http://www.shell-tube.com/Materials-and-Construction.html,

[Accessed: 20-September-2013]

14.Kreyszig, E., Advanced engineering mathematics, John Wiley \& Sons, Inc., USA, 2011.
15.Microsoft巴
SQL
Server ${ }^{\circledR}$ 2012
Express, http://www.microsoft.com/en-us/download/details.aspx?id=29062 http://www.microsoft.com/en-us/sqlserver/editions/2012-editions/enterprise.aspx, [Accessed: 20-September-2013]

16.ISO/IEC 23270:2006 Information technology -- C\# Language Specification, http://www.iso.org/iso/iso_catalogue/catalogue_ics/catalogue_detail_ics.htm?csnumber =42926, [Accessed: 20-September-2013]

17.C\# Language Specification ( $4^{\text {th }}$ edition), Standard Ecma-334 International, Geneve, 2006, http://www.ecma-international.org/publications/files/ECMA-ST/Ecma-334.pdf, [Accessed: 20-September-2013]

18.math.net numerics, http://numerics.mathdotnet.com/api/MathNet.Numerics.LinearAlgebra.Double.Factoriz ation/LU.htm, [Accessed: 20-September-2013] 